\section{Perineural Invasion in Head and Neck Cancer}

Journal of Dental Research 2018, Vol. 97(7) 742-750

(C) International \& American Associations for Dental Research 2018 Reprints and permissions: sagepub.com/journalsPermissions.nav DOI: $10.1177 / 00220345 \mid 8756297$ journals.sagepub.com/home/jdr

\author{
L.B. Schmitd', C.S. Scanlon', and N.J. D'Silva ${ }^{1,2}$
}

\begin{abstract}
Perineural invasion (PNI) is a mechanism of tumor dissemination that can provide a challenge to tumor eradication and that is correlated with poor survival. Squamous cell carcinoma, the most common type of head and neck cancer, has a high prevalence of PNI. This review provides an overview of clinical studies on the outcomes and factors associated with PNI in head and neck cancer and on findings on cancer-nerve crosstalk.
\end{abstract}

Keywords: squamous cell carcinoma, prognosis, metastasis, neoplasm recurrence, neurotrophic factors, galanin

\section{Introduction}

Perineural invasion (PNI) is a mechanism of tumor dissemination via nerves that can provide a challenge to tumor eradication (Amit et al. 2016). PNI is especially common in head and neck, prostate, and colorectal cancers (Liebig et al. 2009). Squamous cell carcinoma (SCC), the most common type of head and neck cancer, has a high prevalence of PNI (Kurtz et al. 2005). It is a neurotropic malignancy - that is, the cancer cells are attracted to nerves (Binmadi and Basile 2011).

Also known as neural invasion, PNI in SCC is highly correlated with poor prognosis (Brandwein-Gensler et al. 2005), including an increased likelihood of metastasis and decreased survival (Rahima et al. 2004; Brandwein-Gensler et al. 2005). This correlation has been attributed in part to spread toward the brainstem and other nerves (Binmadi and Basile 2011), leading to recurrence. PNI increases the likelihood of recurrence in the lymph nodes; detection of PNI in SCC leads to selection of ionizing radiation treatment and/or elective dissection of lymph nodes (Tai, Li, Yang, et al. 2012; Chinn et al. 2013). Initially, PNI is asymptomatic, but pain and paresthesia (Amit et al. 2016) are associated with invasion of large nerves.

Recent mechanistic studies showed that PNI is a dynamic interaction between cancer and nerves. This review discusses the clinical manifestations, outcomes, and factors associated with PNI and the mechanism of PNI in SCC.

\section{Nerve and Perineural Niche}

Peripheral nerves are aggregates of axons and supporting cells and tissues, including Schwann cells, fibroblasts, and blood vessels. Schwann cells maintain and repair myelinated and nonmyelinated axons and produce myelin in the peripheral nervous system (Lowe and Anderson 2014). The axons and capillaries are wrapped by endoneurium, which consists of collagen, extracellular matrix, and fibroblasts. The axons and endoneurium are grouped into fascicles by perineurium, which has 1 or more layer(s) of epithelial-like cells (Lowe and Anderson 2014). These cells are closely associated by tight and adherens junctions and basement membranes on both sides, providing a barrier between the surrounding tissues and axons. Fascicles are grouped by the epineurium, a sheath that surrounds the entire nerve, providing blood supply for the nerves but devoid of lymphatic vessels (Olsson 1990*; for references cited with an asterisk, see Appendix; Fig. 1). The epineurium has an outer layer of loose connective tissue and an inner layer containing collagen and elastic fibers. Blood vessels are frequently found in the perineural niche, as nerves often follow the anatomic vascular distribution throughout the body.

\section{PNI Definition}

Despite the extensive literature about PNI in multiple cancers, the definition is somewhat subjective and has evolved from the first reports of tumor growing along nerves. "Perineural spread" or "clinical PNI" describes symptomatic neural invasion captured by magnetic resonance imaging, while PNI represents the microscopic asymptomatic finding (Panizza 2016). The first description of neurotropism in head and neck cancer defined PNI as "invasion in, around and through" the nerves (Batsakis 1985*). The current widely accepted definition is

'Department of Periodontics and Oral Medicine, School of Dentistry, University of Michigan, Ann Arbor, MI, USA

${ }^{2}$ Department of Pathology, Medical School, University of Michigan, Ann Arbor, MI, USA

A supplemental appendix to this article is available online.

Corresponding Author:

N.J. D'Silva, Department of Periodontics and Oral Medicine, School of Dentistry, University of Michigan, I0I I North University Ave, Room 5217, Ann Arbor, MI 48109-1078, USA

Email:njdsilva@umich.edu 
"tumor in close proximity to nerve and involving at least 33\% of its circumference or tumor cells within any of the 3 layers of the nerve sheath" (Liebig et al. 2009; Fig. 2). Although this definition covers most of the microscopic aspects, including peri- and intraneural invasion, defining "close proximity" and a cutoff of $33 \%$ may be empirical and prone to individual interpretation. Since individual perceptions affect interpretation, there is large variability even among board-certified pathologists on how to detect and describe PNI (Chi et al. 2016). Thus, current definitions are not perfect, and formulating an objective and widely accepted definition for PNI is truly challenging. Moreover, it is unclear if 1 definition should be applied to all cancer types or if tumors with high neurotropism should have a tumor-specific definition that encompasses more information about the nature of tumor-neuronal interactions.

\section{Incidence in SCC}

The term squamous cell carcinoma groups lesions with similar microscopic architecture but with heterogeneity in etiology, clinical behavior, and location. This may have led to the wide variation in PNI rates, from $5.2 \%$ to $90 \%$ (Table 1 ). For example, oral cavity SCC has a high prevalence of neural invasion, while lower lip SCC tends to have a lower prevalence (Rodolico et al. 2004; Ross et al. 2004). Moreover, advanced tumors have high rates of PNI that appear to be independent of location (Carter et al. 1983*; Jardim et al. 2015).

The definitions used can greatly affect the prevalence of PNI reported by each study. While some studies referenced Liebig et al. (2009; Tai, Li, Yang, et al. 2012; Chatzistefanou et al. 2014; Aivazian et al. 2015; Tarsitano et al. 2015), others did not specify the criteria for PNI (Yuen et al. 2000*; Sparano et al. 2004). For example, D'Cruz et al. (2009) reported PNI in 9\% of tongue tumors with unstated criteria, whereas Durr et al. $\left(2013^{*}\right)$ detected PNI in $71 \%$ of a tongue tumor sample using clear criteria.

Another factor that reflects on PNI prevalence is whether it was assessed by review of pathology slides or records. Studies based on records may underestimate PNI depending on when the specimen was examined, since criteria have been repeatedly updated. Furthermore, diagnostic criteria vary among pathologists, and there is less-than-moderate agreement on evaluating PNI in SCC of the oral cavity (Chi et al. 2016).

The use of immunohistochemistry (IHC) to stain nerves can be of value in PNI detection (Kurtz et al. 2005; Shen et al. 2014). Using antiaxonal and antimyelin antibodies, Carter et al. (1983*) described a PNI rate of 33\% (180 noncutaneous head and neck SCC tumor specimens) and $90 \%$ in a small sample of tumor necropsies $(n=20)$. Two studies reported that examination of the nerve trajectory and IHC improves PNI detection in specimens where small nerves are embedded in the tumor or masked by desmoplastic stroma (Kurtz et al. 2005; Shen et al. 2014). Reevaluation of oral cavity SCC by IHC with the use of anti-S100 increased PNI detection from $30 \%$ to $82 \%$ (Kurtz et al. 2005). Both studies highlighted that PNI is underreported, and both supported the use of at least 1 neural marker for analysis of SCC specimens.

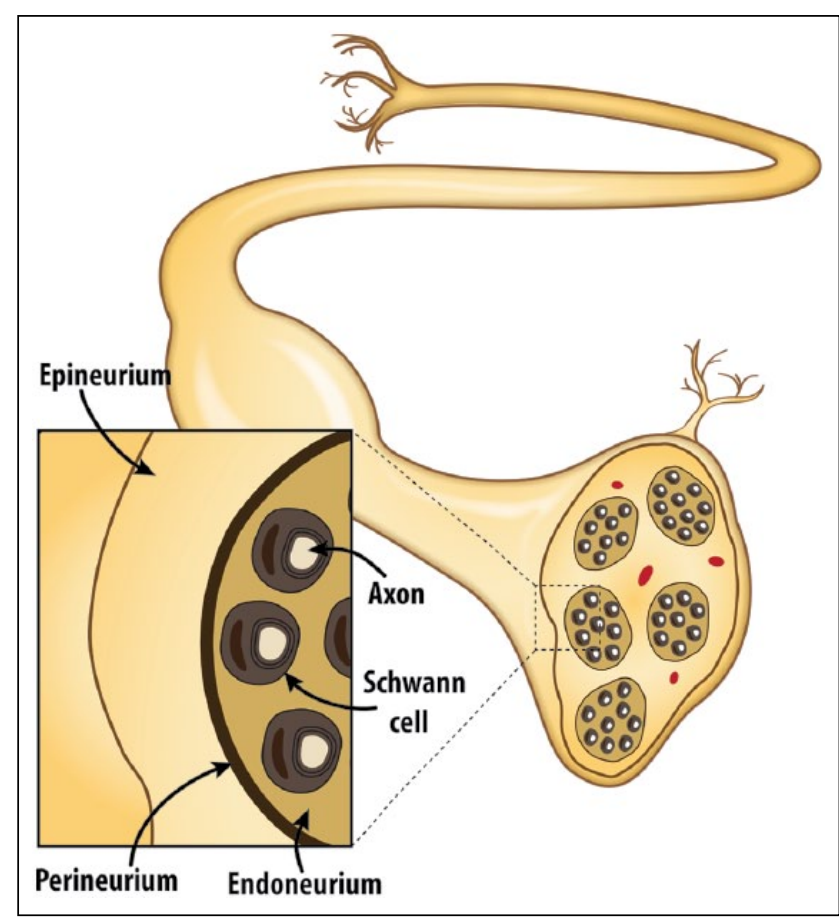

Figure I. Cross-section of a nerve. The axons and endoneurium are grouped into fascicles by perineurium, which is surrounded by the epineurium, a sheath that wraps the entire nerve.

\section{Clinical Outcome}

PNI in head and neck SCC is correlated with poor clinical outcome (Table 2), but some studies showed no change in outcome measures for patients testing positive for PNI (Liao et al. 2008*; Chen et al. 2013*). Factors causing variability in PNI detection also contribute to inconsistencies in patient survival and tumor recurrence. Most studies of prognostic factors in SCC were not designed to investigate the role of PNI in tumor progression and recurrence; some reported PNI as an incidental finding (Yuen et al. 2000*; Larsen et al. 2009). Even when the goal was to analyze PNI, the studies were predominantly retrospective analyses of records of patients with the same cancer type. Retrospective studies have inherent limitations, such as variations in treatment approaches.

PNI status is not associated with human papillomavirus (HPV) positivity (Mendelsohn et al. 2010*). Although worse survival is reported when PNI is present in HPV-associated oropharyngeal cancers (Albergotti et al. 2017*), such association was not significant in a recent meta-analysis (Tassone et al. 2017*). There is evidence that PNI is frequent and associated with higher T-stage in HPV-positive tumors (Albergotti et al. $2017^{*}$ ), similar to the other head and neck SCCs. It is not clear whether PNI is more prevalent among young patients with oral cavity SCC (Soudry et al. 2010*; Hilly et al. 2013*). However, patients $<40$ y old with tongue SCC have worse survival when presenting with PNI (Myers et al. 2000*). When never-smokers were compared with ever-smokers, PNI was associated with higher recurrence rates for both groups (Durr et al. $\left.2013^{*}\right)$. 


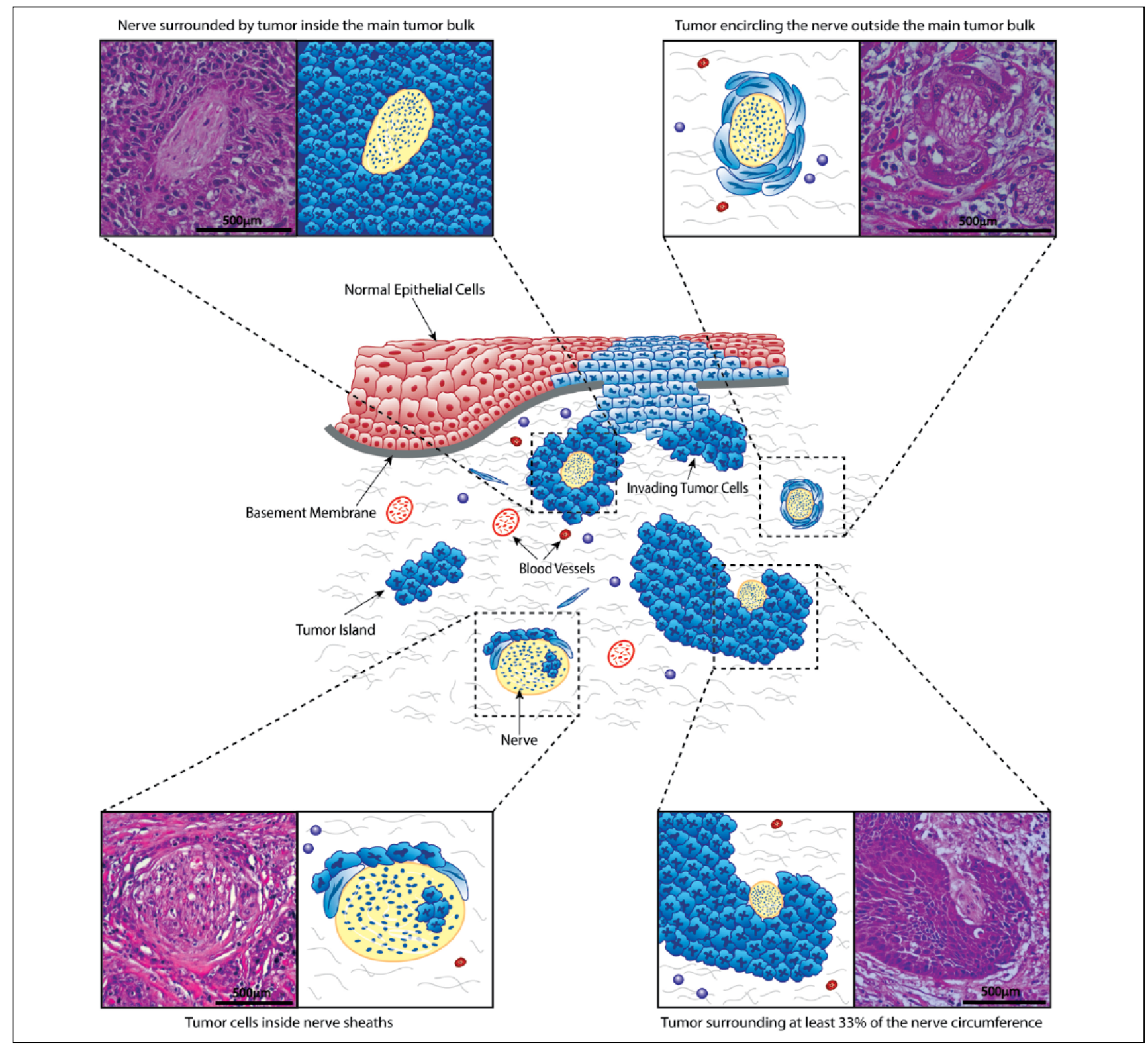

Figure 2. Different phenotypes meeting the current criteria of perineural invasion.

Generally, PNI is associated with poor overall and diseasespecific survival (Table 2). Several studies support that PNI is a predictor of lymph node involvement at the time of diagnosis. The presence of metastasis to the lymph node is a significant prognostic factor in head and neck SCC (Le Tourneau et al. $2005^{*}$ ), with microscopic evaluation of cervical nodes as the most accurate diagnostic method. Investigation of node status $(\mathrm{pN})$ among patients who underwent neck dissection showed that PNI is a significant predictor of occult node metastasis at the time of diagnosis for oral cavity tumors (Ross et al. 2004; Sparano et al. 2004). Other studies confirmed this significant association between PNI and $\mathrm{pN}$ in various stages of oral SCC (Larsen et al. 2009; Chatzistefanou et al. 2014; Jardim et al.
2015), but occult metastases were not separated from patients who were clinically node positive. Of note, for hypopharyngeal and laryngeal tumors, no association between PNI and node metastasis was identified; however, only nerves $<1 \mathrm{~mm}$ in diameter were analyzed (Fagan et al. 1998*). Although it is difficult to draw conclusions for each head and neck site about the role of PNI in predicting node involvement, it seems to be more strongly related to oral cavity tumors, especially tongue tumors (Nair et al. 2016).

Regional recurrence rate appears to be the outcome indicator most affected among patients with PNI, as tumors recur more in the lymph nodes when PNI is detected in the primary tumor. This association is seen in many locations in the head 
Table I. PNI Prevalence in Head and Neck Squamous Cell Carcinoma.

\begin{tabular}{|c|c|c|}
\hline Head and Neck Location & PNI Detection, \% & References \\
\hline Head and neck (various sites) & 7.5 to $52 ; 90^{\mathrm{a}}$ & $\begin{array}{l}\text { Carter et al. 1983*; Soo et al. 1986*; Fagan et al. 1998*; Brandwein-Gensler et al. } \\
\text { 2005; Liao et al. 2008*; Miller et al. 2012; Lanzer et al. 2014* }\end{array}$ \\
\hline Oral cavity (various sites) & 6.1 to 82 & $\begin{array}{l}\text { Hinerman et al. 2004*; Kurtz et al. 2005; Tai, Li, Chu, et al. 20I2; Chinn et al. 20I3; } \\
\text { Tai et al. 20I3; Aivazian et al. 20I5; Lin et al. 20I5*; Tarsitano et al. 20I5; Garzino- } \\
\text { Demo et al. 2016*; Nair et al. 20I6 }\end{array}$ \\
\hline Tongue and/or floor of the mouth & 6 to 71 & $\begin{array}{l}\text { Brown et al. 1989*; Sparano et al. 2004; D'Cruz et al. 2009; Tai, Li, Yang, et al. 20I2; } \\
\text { Durr et al. 2013*; Ling et al. 2013*; Jardim et al. 20I5; Nair et al. } 2016\end{array}$ \\
\hline Lower lip & 5.2 & Rodolico et al. 2004 \\
\hline Oral cavity + oropharynx & 26.3 to 72.1 & Fagan et al. 1998*; Ross et al. 2004; González-García et al. 2009 \\
\hline Oropharynx & 21.6 to 50 & Soo et al. 1986*; Rahima et al. 2004 \\
\hline Larynx & 19.3 to 61.5 & Carter et al. 1983*; Soo et al. 1986*; Fletcher et al. 2017* \\
\hline Larynx + hypopharynx & 46 & Fagan et al. 1998* \\
\hline Nose and paranasal sinuses & 25 to 46.2 & Carter et al. 1983*; Soo et al. 1986* \\
\hline
\end{tabular}

PNI, perineural invasion.

${ }^{a}$ From a necropsy series of 20 tumors (Carter et al. 1983).

*References cited with an asterisk are provided in the Appendix.

Table 2. Head and Neck Squamous Cell Carcinoma Outcomes Related to PNI Detected by Microscopic Analysis.

\begin{tabular}{|c|c|}
\hline Outcome Measure Associated with PNI & References \\
\hline Overall survival $^{\mathrm{a}}$ & 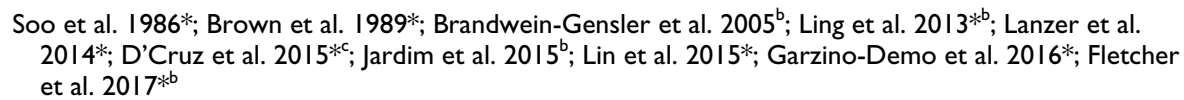 \\
\hline Disease-specific survival ${ }^{d}$ & $\begin{array}{l}\text { Soo et al. 1986*; Brown et al. 1989*; Fagan et al. 1998*; Yuen et al. 2000*; Hinerman et al. 2004*b; Tai, } \\
\text { Li, Chu, et al. 20I2b; Tai, Li, Yang, et al. 20I2; Chinn et al. 20I3; Ling et al. 2013*b; Aivazian et al. } \\
\text { 20I5 } 5^{\text {be, }} \text { Lin et al. 20I5*; Garzino-Demo et al. 2016* }\end{array}$ \\
\hline \multicolumn{2}{|r|}{ - } \\
\hline Local recurrence & $\begin{array}{l}\text { Fagan et al. 1998*; Yuen et al. 2000*; Rahima et al. 2004; Brandwein-Gensler et al. 2005; Aivazian et al. } \\
\text { 20I5 } 5^{\text {eff; }} \text { Tarsitano et al. 2015 }\end{array}$ \\
\hline Locoregional recurrence & Hinerman et al. $2004^{* b}$; Durr et al. $2013^{* b}$; Chinn et al. $2013^{\text {b }}$; Jardim et al. 2015 ; Lin et al. $2015^{*}$ \\
\hline Regional recurrence (neck recurrence) & 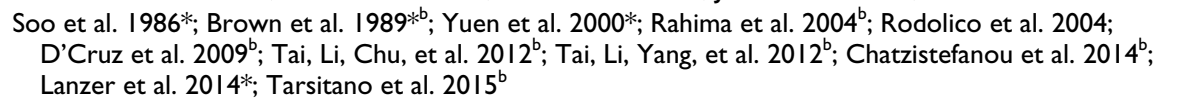 \\
\hline Distant metastasis & Rahima et al. $2004^{\mathrm{b}}$ \\
\hline Presence of occult neck metastasis & Ross et al. 2004; Sparano et al. 2004; Nair et al. $2016^{\mathrm{b}}$ \\
\hline Presence of neck metastasis at diagnosis & 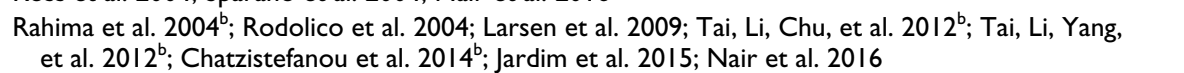 \\
\hline
\end{tabular}

PNI, perineural invasion.

${ }^{a}$ Overall survival considers deaths from all causes.

bIndependent predictor.

'Prospective study.

${ }^{d}$ Disease-specific survival considers deaths only from the squamous cell carcinoma.

${ }^{\mathrm{e}}$ For multifocal PNI.

${ }^{f}$ For nerves $\geq \mathrm{I} \mathrm{mm}$ diameter.

*References cited with an asterisk are provided in the Appendix.

and neck (Table 2). Oral cavity tumors with PNI are particularly prone to neck recurrence, and PNI is often reported as an independent predictor of node involvement (D'Cruz et al. 2009; Tai, Li, Chu, et al. 2012; Tai, Li, Yang, et al. 2012; Chinn et al. 2013; Chatzistefanou et al. 2014). Rahima et al. (2004) reported PNI as an independent predictor of regional recurrence in a mixed sample of oral cavity and oropharynx SCC, and Tarsitano et al. (2015) showed this correlation for oral cavity tumors. For other head and neck sites, such as lower lip, larynx, and oropharynx, there is evidence of PNI as a significant but not independent predictor of subsequent neck metastasis (Soo et al. 1986*; Rodolico et al. 2004).
Although PNI affects node status and node recurrence, there is some evidence for association with local recurrence. In a retrospective study of 522 patients with oral cavity SCC, there was no association between PNI and local recurrence or second primary tumors (González-García et al. 2009). Among studies that found a significant association between local recurrence and PNI (Rahima et al. 2004; Brandwein-Gensler et al. 2005; Aivazian et al. 2015; Tarsitano et al. 2015), only a few were able to show PNI as an independent predictor of local recurrence (Brandwein-Gensler et al. 2005; Tarsitano et al. 2015). Brandwein-Gensler et al. (2005) reported an independent association between higher local recurrence rate and PNI 
only if the PNI occurred in nerves $>1 \mathrm{~mm}$ in diameter, while Tarsitano et al. (2015) reported similar findings regardless of nerve size.

The pathophysiology of invasion and metastasis in PNI is currently unknown. PNI could be present in a more aggressive subset of tumors, reflecting the development of node metastasis, but the actual role of PNI is unclear. Tumors with PNI may have poorer margin control, with spread along the nerve beyond the surgical margins at the time of treatment (Tarsitano et al. 2015). To better understand the impact on patient outcome, PNI can be subcategorized according to location, size, and number of nerves affected (Fagan et al. 1998*; BrandweinGensler et al. 2005; Miller et al. 2012; Chinn et al. 2013; Aivazian et al. 2015; Tarsitano et al. 2015). Chinn et al. (2013) categorized the extent of PNI as focal (1 focus), moderate ( 2 to 5 foci), and extensive ( $>5$ foci), and the affected nerves were subdivided as small $(<1 \mathrm{~mm})$ and large $(\geq 1 \mathrm{~mm})$. They found no correlation between the categories and outcome measures. Using the same categories in a much larger sample, Tarsitano et al. (2015) reported significantly higher local failure for extensive PNI. Aivazian et al. (2015) scored PNI as unifocal (1 nerve) versus multifocal (multiple nerves) and also categorized nerves into size groups. Local failure was significantly higher for the patients with PNI in nerves $\geq 1 \mathrm{~mm}$, similar to a previous report (Brandwein-Gensler et al. 2005), as well as for the tumors with multifocal PNI, suggesting that extension of PNI is an important measure of aggressiveness. Perhaps the first attempt to subcategorize PNI by location relative to tumor was published by Miller et al. (2012), who found that extent of PNI outside the tumor edge was significantly correlated with the length of disease-free survival. They classified PNI as absent, intratumoral (inside tumor bulk), and extratumoral (outside tumor edge), which was subdivided into peripheral when the affected nerve was within 0 to $0.2 \mathrm{~mm}$ from the tumor edge. Interestingly, this study did not find that PNI alone correlated with disease-free survival but that extratumoral and peripheral PNI was associated with reduced time to recurrence. However, these results were not replicated by Tarsitano et al. (2015). Referencing extratumoral PNI from Miller et al. (2012), the College of American Pathologists' Cancer Protocols (http:// www.cap.org) recommends inclusion of "extent of PNI" in pathology reports for oral cavity SCC.

\section{Molecular Markers and Regulation}

PNI can provide a challenge to complete resection (Rahima et al. 2004; Tarsitano et al. 2015), presumably due to neural extension away from the primary tumor to a distant site that is missed during evaluation of surgical margins (Binmadi et al. 2012). Given the higher lymph node recurrence and poorer survival associated with PNI, more aggressive treatment has been proposed, including adjuvant therapies such as elective neck dissection and/or radiation (Fagan et al. 1998*; Chinn et al. 2013; Tai et al. 2013). However, the value of these treatments relative to patients' outcome is still uncertain (D'Cruz et al. 2015*; Bur et al. 2016). Characterization of the interaction between nerves and cancer is important for developing treatment strategies that directly target neural invasion and for adoption of personalized medicine approaches to treat patients with PNI.

PNI is a relatively understudied route of tumor dissemination. Early studies suggested that tumor cells engaged nerves to spread easily to other tissues or that PNI was a type of lymphatic invasion (Liebig et al. 2009). The evolution of knowledge about nerve structure and microenvironment provided the basis of the current understanding that PNI is a complex interaction between nerves and tumor cells. Cancer cells breach the perineurium to gain access to Schwann cells and axons within the endoneurium (Bakst and Wong 2016), and nerves send neurites toward the cancer-enhancing neurotropism (Ayala et al. 2008; Scanlon et al. 2015).

PNI is mediated by molecular signals that initiate and drive the process, promoting proliferation, survival, and invasion of cancer cells and neuritogenesis (Ayala et al. 2008; Marchesi et al. 2010; Scanlon et al. 2015; Amit et al. 2016). The mechanisms regulating these phenotypes are discussed with an emphasis on SCC of the head and neck.

Invasion of cancer cells into the perineurium and movement along the nerve require crosstalk that likely capitalizes on nerve-regenerative processes and may be mediated via cells in the perineural niche, soluble factors, and their receptors (Amit et al. 2016). Included in this group are growth factors, proteins regulating chemotaxis, extracellular matrix adhesion proteins, macrophages, stellate cells, and Schwann cells (Amit et al. 2016). In SCC, most studies on these proteins investigated expression of protein or transcript in regions of PNI (Table 3); mechanistic studies are sparse. However, the disparity in neurotropism in SCC in different patients emphasizes the need for mechanistic studies to elucidate this important route of tumor dissemination.

\section{Neurotrophins}

Neurotrophins are proteins that, with their receptors, promote neuronal growth and PNI (Liebig et al. 2009). Neurotrophins investigated in SCC include nerve growth factor (NGF), brainderived neurotropic factor (BDNF), and glial cell line-derived neurotrophic factor (GDNF).

$N G F$ is a neurotrophic peptide that has been linked to PNI in multiple cancers (Kolokythas et al. 2010). NGF and TrkA, its receptor tyrosine kinase, are upregulated in SCC adjacent to areas of PNI (Kolokythas et al. 2010). Studies on oral SCC showed that NGF expression in cancer cells was correlated with PNI and lymph node metastasis - poor prognostic factors (Shen et al. 2014; Yu et al. 2014); TrkA did not show a similar correlation (Yu et al. 2014). NGFR or $\mathrm{p} 75^{\mathrm{NTR}}$ is a low-affinity receptor for NGF that promotes invasion and spread in SCC (Chen et al. 2016). The mechanistic significance of NGF in SCC remains to be elucidated.

$B D N F$ promotes growth and differentiation of the nervous system (Bakst and Wong 2016). Adenoid cystic carcinoma, a neurotropic tumor in the head and neck region, exhibits diffuse 
Table 3. Molecular Markers of PNI in Head and Neck SCC.

\begin{tabular}{|c|c|c|c|}
\hline Molecular Marker & Class & Relevance & References \\
\hline NGF (nerve growth factor) & Neurotrophin & $\begin{array}{l}\text { Expression associated with PNI, worse } \\
\text { survival, and node metastasis; NGFR } \\
\text { increases invasive phenotype of SCC } \\
\text { xenografts }\end{array}$ & $\begin{array}{l}\text { Kolokythas et al. 20I0; Shen et al. } \\
2014 \text {; Yu et al. 2014; Chen et al. } \\
2016\end{array}$ \\
\hline $\begin{array}{l}\text { BDNF (brain-derived neurotrophic } \\
\text { factor) }\end{array}$ & Neurotrophin & $\begin{array}{l}\text { Overexpression of TrkB (BDNF } \\
\text { receptor) induces EMT }\end{array}$ & Kupferman et al. 2010 \\
\hline $\begin{array}{l}\text { GDNF (glial-derived neurotrophic } \\
\text { factor), artemin }\end{array}$ & Neurotrophin & $\begin{array}{l}\text { GDNF seems to regulate cancer } \\
\text { cell migration; artemin expression } \\
\text { associated with late-stage disease }\end{array}$ & Chuang et al. 2013; Gao et al. 2014 \\
\hline Semaphorin 4D & Axon guidance protein & $\begin{array}{l}\text { Axogenesis, high nerve density in } \\
\text { xenografted tumors }\end{array}$ & Binmadi et al. 2012 \\
\hline Slit-Robo & $\begin{array}{l}\text { Axon guidance and } \\
\text { chemotactic protein }\end{array}$ & Slit- 2 decreases SCC cell migration & Bauer et al. 201 I \\
\hline Galanin & Neuropeptide & $\begin{array}{l}\text { Promotes cancer invasion and } \\
\text { neuritogenesis }\end{array}$ & Scanlon et al. 2015 \\
\hline $\begin{array}{l}\text { CX3CLI / CX3CRI (fractalkine } \\
\text { and fractalkine receptor) }\end{array}$ & Chemotaxis protein & $\begin{array}{l}\text { Expression of } \mathrm{CX} 3 \mathrm{CLI} \text { not associated } \\
\text { with } \mathrm{PNI}\end{array}$ & Doumas et al. 2015 \\
\hline Galectin I & Chemotaxis protein & $\begin{array}{l}\text { Perineural lymphocytic infiltrate } \\
\text { expression of galectin I associated } \\
\text { with poor outcome }\end{array}$ & Chawla et al. 2016 \\
\hline Cytokine A & Chemotaxis protein & $\begin{array}{l}\text { Expression associated with PNI and } \\
\text { worse survival }\end{array}$ & Chang et al. 2010 \\
\hline $\begin{array}{l}\text { NCAM (neural cell adhesion } \\
\text { molecule) }\end{array}$ & ECM adhesion protein & Expression associated with PNI & Vural et al $2000^{*}$ \\
\hline Laminin 5 & ECM adhesion protein & Expression associated with PNI & $\begin{array}{l}\text { Anderson et al. 2001; Tarsitano } \\
\text { et al. } 2016\end{array}$ \\
\hline ICAM-5 (telencephalin) & Intercellular adhesion protein & Expression associated with PNI & Maruya et al. 2005 \\
\hline Claudin I & Intercellular adhesion protein & Expression associated with PNI & $\begin{array}{l}\text { Dos Reis et al. 2008; Sappayatosok } \\
\text { and Phattarataratip } 2015\end{array}$ \\
\hline $\begin{array}{l}\text { IMP3 (IGF-II mRNA binding } \\
\text { protein 3) }\end{array}$ & mRNA binding protein & $\begin{array}{l}\text { Expression associated with } \mathrm{PNI} \text { and } \\
\text { independent predictor of death }\end{array}$ & Tarsitano et al. 2016 \\
\hline BAGI and Bim/Bod & $\begin{array}{l}\text { Anti- and proapoptotic } \\
\text { proteins }\end{array}$ & Expression associated with PNI & Coutinho-Camillo et al. 2010 \\
\hline
\end{tabular}

EMT, epithelial-to-mesenchymal transition; PNI, perineural invasion; SCC, squamous cell carcinoma.

*Reference cited with an asterisk is provided in the Appendix.

cytoplasmic expression of BDNF regardless of the presence of PNI (Kowalski and Paulino 2002). Although BDNF has not been investigated in SCC, tropomyosin-related kinase-B receptor - a receptor tyrosine kinase that is activated by BDNF and neurotrophic factor 4-regulates invasion in SCC (Kupferman et al. 2010). Given its important role in the nervous system and in invasion in SCC, investigation of BDNF's role in PNI may be relevant to tumor progression. Furthermore, exploration of the role of neurotrophin 4 in PNI would be important.

$G D N F$ is a structurally distinct family of neurotrophins that includes GDNF, neurturin, artemin, and persephin, which signal through RET, a receptor tyrosine kinase (Bakst and Wong 2016). In SCC, GDNF promotes cell migration via MAP kinase, AP-1 transcription factor, and matrix metalloproteinases (Chuang et al. 2013), but its role in PNI is unclear. In pancreatic cancer, GDNF secretion by dorsal root ganglia promotes invasion of cancer cells into the ganglia (He et al. 2014).

Artemin, a member of the GDNF family, is overexpressed in human laryngeal SCC and is associated with poor survival and high tumor stage (Gao et al. 2014). In pancreatic cancer cell lines, artemin enhances neurotropic invasion (Gao et al. 2015), but the association between artemin and PNI has not been investigated in SCC.

\section{Factors Promoting Neuritogenesis}

Cancer enhances axonogenesis or neurite outgrowth, which appears to be essential for PNI (Ayala et al. 2008; Scanlon et al. 2015). Proteins that regulate axon guidance have a significant role in cancer (Bakst and Wong 2016).

Semaphorin 4D has both attractive and repulsive functions; membrane-bound semaphorin 4D repels neurites, whereas secreted protein promotes neurite outgrowth (Sakai et al. 1999*; Fuchikawa et al. 2009). Semaphorin 4D in SCC was correlated with axonogenesis (Binmadi et al. 2012). SCC xenografts with high expression of semaphorin D exhibited higher nerve density and neuritogenesis.

Slit ligands bind to membrane-bound roundabout (Robo) receptors to repel axon growth and branching ( $\mathrm{Li}$ et al. 1999*). SLIT2, which binds to Robo3, inhibits migration in SCC (Bauer et al. 2011). Although SLIT2's role in PNI in SCC has 


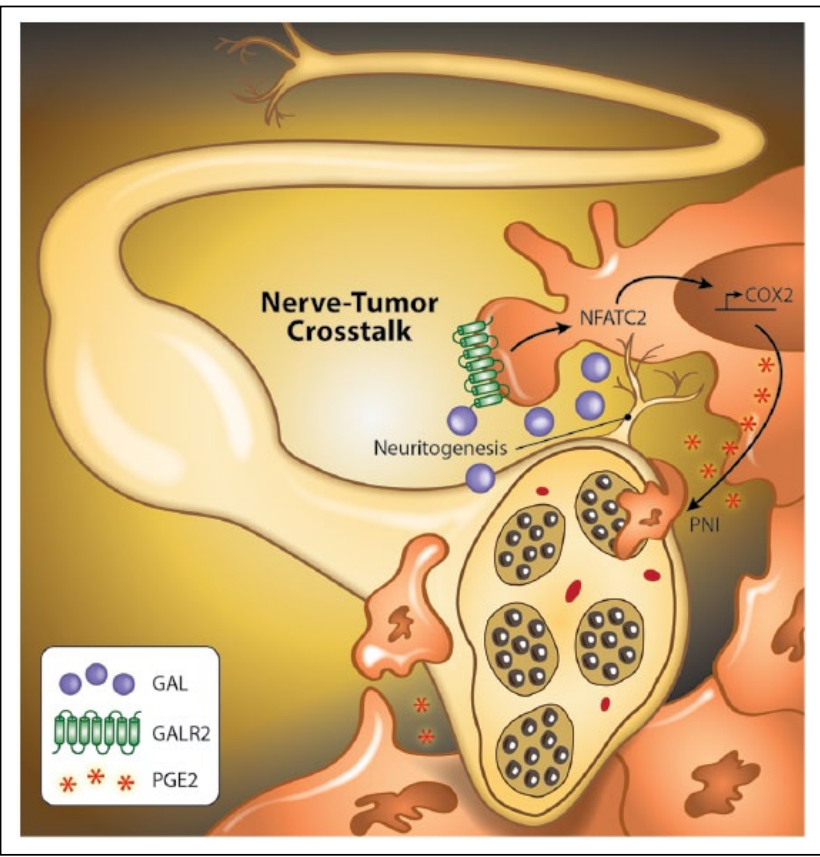

Figure 3. Galanin secreted by nerves induces GALR2 on SCC cells. SCC-secreted galanin and PGE2 induce neuritogenesis and invasion, respectively. PGE2, prostaglandin E2; PNI, perineural invasion; SCC, squamous cell carcinoma.

not been investigated, in vitro studies in pancreatic cancer showed that a reduction in SLIT2 allows migration of cancer cells along neurites (Gohrig et al. 2014).

\section{Proteins Regulating Chemotaxis}

Galanin, a neuropeptide and putative trophic factor, binds to galanin receptors GALR1, GALR2, and GALR3, also known as $\mathrm{GAL}_{1}, \mathrm{GAL}_{2}$, and $\mathrm{GAL}_{3}$ (Lang et al. 2015). GALR1 and GALR2 have antagonistic roles in SCC: GALR1 is a tumor suppressor (Henson et al. 2005), whereas GALR2 promotes tumor growth (Banerjee et al. 2011). Consequently, overexpression of GALR2 or reduced expression of GALR1 can enhance GALR2-induced signaling cascades and functional effects. Based on in vitro and in vivo approaches - including the chick embryo chorioallantoic membrane-dorsal root ganglia model system for $\mathrm{SCC}$ - a recent mechanistic study showed that neural-derived galanin induces GALR2 on SCC cells to promote neural invasion (Scanlon et al. 2015). GALR2 on SCC cells induces NFATc2-mediated transcription of galanin and cyclooxygenase 2 with consequent secretion of galanin and prostaglandin E2 (PGE2), respectively. SCCsecreted galanin and PGE2 induce neuritogenesis and invasion, respectively (Fig. 3).

CX3CL1 and its receptor CX3CR1 - also known as fractalkine and fractalkine receptor, respectively - promote neurotropism in pancreatic cancers (Marchesi et al. 2010). SCC, with or without PNI, was positive for CX3CL1 but negative for CX3CR1 (Doumas et al. 2015).

Galectin 1 has been linked to multiple oncogenic phenotypes. In a small study of cutaneous SCC of the head and neck, high galectin staining in the lymphocyte populations adjacent to areas of perineural spread was associated with poor diseasefree survival and overall survival (Chawla et al. 2016). While the mechanistic role of galectin 1 in PNI has not been investigated in any cancer, galectin 1 promotes invasion in pancreatic ductal adenocarcinoma (Tang et al. 2014).

The cytokine activin $\mathrm{A}$ is a member of the transforming growth factor $\beta$ family (Chang et al. 2010). Overexpression of activin A in the cytoplasm of SCC cells was associated with PNI and poor overall and disease-free survival. Although downregulation of activin A inhibits invasion, migration, and proliferation of SCC, its role in PNI is unclear (Chang et al. 2010).

\section{Extracellular Matrix Adhesion Proteins}

Cell adhesion molecules promote invasion and spread of multiple cancers via cell-cell and cell-matrix interactions (Bakst and Wong 2016). Neural cell adhesion molecule (NCAM) is expressed on Schwann cells and neurons (Bakst and Wong 2016). In SCC from multiple sites in the head and neck, NCAM was reported in more tumors with PNI than without (Vural et al. 2000*). Given the importance of NCAM on Schwann cells in PNI in pancreatic adenocarcinomas (Deborde et al. 2016), it could be beneficial to clarify the role of NCAM in SCC.

Laminin 5 is an extracellular matrix protein that is overexpressed in tumor cells of PNI-positive SCC versus PNInegative SCC (Anderson et al. 2001). Detection of laminin 5 in SCC cells on diagnostic biopsies was correlated with detection of PNI in subsequent surgical specimens (Tarsitano et al. 2016).

ICAM-5 or telencephalin is a cell adhesion molecule that is overexpressed in SCC and associated with PNI (Maruya et al. 2005).

Claudin 1 and claudin 4 are transmembrane proteins of the tight junction complex that are essential for its function. Claudin 1 expression in SCC is associated with PNI (Dos Reis et al. 2008; Sappayatosok and Phattarataratip 2015), whereas PNI decreased when claudin 4 expression was high. Overexpression of claudin 1 in SCC cells promotes invasion (Dos Reis et al. 2008).

Insulin-like growth factor II mRNA binding protein 3 (IMP3) is an RNA-binding protein that enhances translation of insulin-like growth factor II mRNA (Tarsitano et al. 2016). In diagnostic incisional biopsies, IMP3 is strongly predictive of PNI in surgical specimens and is an independent predictor of death (Tarsitano et al. 2015).

Bim/Bod and BAG1 are proteins that promote and inhibit apoptosis, respectively. Increased expression of these proteins in tumor cells of SCC tissue was associated with PNI (Coutinho-Camillo et al. 2010).

\section{Cells in the Neural Microenvironment}

Schwann cells have a crucial role in neural regeneration (Amit et al. 2016). These glial-type cells are highly prevalent in peripheral nerves and migrate toward pancreatic and colon cancers (Demir et al. 2014; Deborde et al. 2016). Although the role of Schwann cells in SCC has not been investigated, other less 
common head and neck cancers with a high prevalence of PNI exhibit neuronal differentiation of cancer cells. For example, myoepithelial cells in adenoid cystic carcinoma salivary gland tumors, which frequently exhibit PNI, undergo Schwann cell differentiation (Chen et al. 2012). The role of endoneurial macrophages and stellate cells has not been investigated in SCC.

\section{Conclusion}

In SCC, most studies investigated expression of protein or transcript in regions of PNI but not specific mechanisms of neural invasion. The neurotropism of SCC emphasizes the need for mechanistic studies to elucidate this important route of tumor dissemination. Furthermore, efforts should be made to unravel mechanisms behind the high association between neural invasion and lymph node metastasis.

\section{Author Contributions}

L.B. Schmitd, C.S. Scanlon, N.J. D'Silva, contributed to conception and design, drafted and critically revised the manuscript. All authors gave final approval and agree to be accountable for all aspects of the work.

\section{Acknowledgments}

This work was supported by the National Institutes of Health (National Institute of Dental and Craniofacial Research grants DE027551, DE022567, DE024384), the Department of Periodontics and Oral Medicine of the University of Michigan (clinical research grant to N.J.D.), and the National Institutes of Health (National Institute of Dental and Craniofacial Research grant DE021293 to C.S.S). The authors declare no potential conflicts of interest with respect to the authorship and/or publication of this article.

\section{References}

*For references cited with an asterisk, see Appendix.

Aivazian K, Ebrahimi A, Low TH, Gao K, Clifford A, Shannon K, Clark JR, Gupta R. 2015. Perineural invasion in oral squamous cell carcinoma: quantitative subcategorisation of perineural invasion and prognostication. J Surg Oncol. 111(3):352-358.

Amit M, Na'ara S, Gil Z. 2016. Mechanisms of cancer dissemination along nerves. Nat Rev Cancer. 16(6):399-408.

Anderson TD, Feldman M, Weber RS, Ziober AF, Ziober BL. 2001. Tumor deposition of laminin-5 and the relationship with perineural invasion. Laryngoscope. 111(12):2140-2143.

Ayala GE, Dai H, Powell M, Li R, Ding Y, Wheeler TM, Shine D, Kadmon D, Thompson T, Miles BJ, et al. 2008. Cancer-related axonogenesis and neurogenesis in prostate cancer. Clin Cancer Res. 14(23):7593-7603.

Bakst RL, Wong RJ. 2016. Mechanisms of perineural invasion. J Neurol Surg B Skull Base. 77(2):96-106

Banerjee R, Henson BS, Russo N, Tsodikov A, D’Silva NJ. 2011. Rap1 mediates galanin receptor 2-induced proliferation and survival in squamous cell carcinoma. Cell Signal. 23(7):1110-1118.

Bauer K, Dowejko A, Bosserhoff AK, Reichert TE, Bauer R. 2011. Slit-2 facilitates interaction of P-cadherin with Robo-3 and inhibits cell migration in an oral squamous cell carcinoma cell line. Carcinogenesis. 32(6):935-943.

Binmadi NO, Basile JR. 2011. Perineural invasion in oral squamous cell carcinoma: a discussion of significance and review of the literature. Oral Oncol. 47(11):1005-1010.

Binmadi NO, Yang YH, Zhou H, Proia P, Lin YL, De Paula AM, Guimaraes AL, Poswar FO, Sundararajan D, Basile JR. 2012. Plexin-B1 and semaphorin 4D cooperate to promote perineural invasion in a RhoA/ROK-dependent manner. Am J Pathol. 180(3):1232-1242.
Brandwein-Gensler M, Teixeira MS, Lewis CM, Lee B, Rolnitzky L, Hille JJ, Genden E, Urken ML, Wang BY. 2005. Oral squamous cell carcinoma: histologic risk assessment, but not margin status, is strongly predictive of local disease-free and overall survival. Am J Surg Pathol. 29(2):167-178.

Bur AM, Lin A, Weinstein GS. 2016. Adjuvant radiotherapy for early head and neck squamous cell carcinoma with perineural invasion: a systematic review. Head Neck. 38 Suppl 1:E2350-E2357.

Chang KP, Kao HK, Liang Y, Cheng MH, Chang YL, Liu SC, Lin YC, Ko TY, Lee YS, Tsai CL, et al. 2010. Overexpression of activin a in oral squamous cell carcinoma: association with poor prognosis and tumor progression. Ann Surg Oncol. 17(7):1945-1956.

Chatzistefanou I, Lubek J, Markou K, Ord RA. 2014. The role of neck dissection and postoperative adjuvant radiotherapy in $\mathrm{cN} 0$ patients with PNI-positive squamous cell carcinoma of the oral cavity. Oral Oncol. 50(8):753-758.

Chawla S, Warren TA, Wockner LF, Lambie DL, Brown IS, Martin TP, Khanna R, Leggatt GR, Panizza BJ. 2016. Galectin-1 is associated with poor prognosis in patients with cutaneous head and neck cancer with perineural spread. Cancer Immunol Immunother. 65(2):213-222.

Chen C, Shin JH, Eggold JT, Chung MK, Zhang LH, Lee J, Sunwoo JB. 2016 ESM1 mediates NGFR-induced invasion and metastasis in murine oral squamous cell carcinoma. Oncotarget. 7(43):70738-70749.

Chen W, Dong S, Zhou J, Sun M. 2012. Investigation of myoepithelial cell differentiation into Schwann-like cells in salivary adenoid cystic carcinoma associated with perineural invasion. Mol Med Rep. 6(4):755-759.

Chi AC, Katabi N, Chen HS, Cheng YL. 2016. Interobserver variation among pathologists in evaluating perineural invasion for oral squamous cell carcinoma. Head Neck Pathol. 10(4):451-464.

Chinn SB, Spector ME, Bellile EL, McHugh JB, Gernon TJ, Bradford CR, Wolf GT, Eisbruch A, Chepeha DB. 2013. Impact of perineural invasion in the pathologically N0 neck in oral cavity squamous cell carcinoma. Otolaryngol Head Neck Surg. 149(6):893-899.

Chuang JY, Tsai CF, Chang SW, Chiang IP, Huang SM, Lin HY, Yeh WL, Lu DY. 2013. Glial cell line-derived neurotrophic factor induces cell migration in human oral squamous cell carcinoma. Oral Oncol. 49(12):1103-1112.

Coutinho-Camillo CM, Lourenco SV, Nishimoto IN, Kowalski LP, Soares FA. 2010. Expression of Bcl-2 family proteins and association with clinicopathological characteristics of oral squamous cell carcinoma. Histopathology. 57(2):304-316.

D'Cruz AK, Siddachari RC, Walvekar RR, Pantvaidya GH, Chaukar DA, Deshpande MS, Pai PS, Chaturvedi P. 2009. Elective neck dissection for the management of the N0 neck in early cancer of the oral tongue: need for a randomized controlled trial. Head Neck. 31(5):618-624.

Deborde S, Omelchenko T, Lyubchik A, Zhou Y, He S, McNamara WF, Chernichenko N, Lee SY, Barajas F, Chen CH, et al. 2016. Schwann cells induce cancer cell dispersion and invasion. J Clin Invest. 126(4):15381554

Demir IE, Boldis A, Pfitzinger PL, Teller S, Brunner E, Klose N, Kehl T, Maak M, Lesina M, Laschinger M, et al. 2014. Investigation of Schwann cells at neoplastic cell sites before the onset of cancer invasion. J Natl Cancer Inst. 106(8):dju184.

Dos Reis PP, Bharadwaj RR, Machado J, Macmillan C, Pintilie M, Sukhai MA, Perez-Ordonez B, Gullane P, Irish J, Kamel-Reid S. 2008. Claudin 1 overexpression increases invasion and is associated with aggressive histological features in oral squamous cell carcinoma. Cancer. 113(11):3169-3180.

Doumas S, Paterson JC, Norris PM, Tighe JV, Newman L, Bisase BS, Kolokotronis AE, Barrett AW. 2015. Fractalkine (CX3CL1) and fractalkine receptor (CX3CR1) in squamous cell carcinoma of the tongue: markers of nerve invasion? Oral Maxillofac Surg. 19(1):61-64.

Fuchikawa T, Nakamura F, Fukuda N, Takei K, Goshima Y. 2009. Protein tyrosine phosphatase SHP2 is involved in semaphorin 4D-induced axon repulsion. Biochem Biophys Res Commun. 385(1):6-10.

Gao C, Cheng X, Li X, Tong B, Wu K, Liu Y. 2014. Prognostic significance of artemin and GFR $\alpha 1$ expression in laryngeal squamous cell carcinoma. Exp Ther Med. 8(3):818-822.

Gao L, Bo H, Wang Y, Zhang J, Zhu M. 2015. Neurotrophic factor artemin promotes invasiveness and neurotrophic function of pancreatic adenocarcinoma in vivo and in vitro. Pancreas. 44(1):134-143.

Gohrig A, Detjen KM, Hilfenhaus G, Korner JL, Welzel M, Arsenic R, Schmuck R, Bahra M, Wu JY, Wiedenmann B, et al. 2014. Axon guidance factor SLIT2 inhibits neural invasion and metastasis in pancreatic cancer. Cancer Res. 74(5):1529-1540.

González-García R, Naval-Gías L, Román-Romero L, Sastre-Pérez J, Rodríguez-Campo FJ. 2009. Local recurrences and second primary tumors from squamous cell carcinoma of the oral cavity: a retrospective analytic study of 500 patients. Head Neck. 31(9):1168-1180. 
He S, Chen CH, Chernichenko N, He S, Bakst RL, Barajas F, Deborde S, Allen PJ, Vakiani E, Yu Z, et al. 2014. GFR $\alpha 1$ released by nerves enhances cancer cell perineural invasion through GDNF-RET signaling. Proc Natl Acad Sci U S A. 111(19):E2008-E2017.

Henson BS, Neubig RR, Jang I, Ogawa T, Zhang Z, Carey TE, D'Silva NJ. 2005. Galanin receptor 1 has anti-proliferative effects in oral squamous cell carcinoma. J Biol Chem. 280(24):22564-22571.

Jardim JF, Francisco AL, Gondak R, Damascena A, Kowalski LP. 2015. Prognostic impact of perineural invasion and lymphovascular invasion in advanced stage oral squamous cell carcinoma. Int J Oral Maxillofac Surg. 44(1):23-28.

Kolokythas A, Cox DP, Dekker N, Schmidt BL. 2010. Nerve growth factor and tyrosine kinase A receptor in oral squamous cell carcinoma: is there an association with perineural invasion? J Oral Maxillofac Surg. 68(6):1290-1295.

Kowalski PJ, Paulino AF. 2002. Perineural invasion in adenoid cystic carcinoma: its causation/promotion by brain-derived neurotrophic factor. Hum Pathol. 33(9):933-936.

Kupferman ME, Jiffar T, El-Naggar A, Yilmaz T, Zhou G, Xie T, Feng L, Wang J, Holsinger FC, Yu D, et al. 2010. TrkB induces EMT and has a key role in invasion of head and neck squamous cell carcinoma. Oncogene. 29(14):2047-2059.

Kurtz KA, Hoffman HT, Zimmerman MB, Robinson RA. 2005. Perineural and vascular invasion in oral cavity squamous carcinoma: increased incidence on re-review of slides and by using immunohistochemical enhancement. Arch Pathol Lab Med. 129(3):354-359.

Lang R, Gundlach AL, Holmes FE, Hobson SA, Wynick D, Hokfelt T, Kofler B. 2015. Physiology, signaling, and pharmacology of galanin peptides and receptors: three decades of emerging diversity. Pharmacol Rev. 67(1):118175.

Larsen SR, Johansen J, Sorensen JA, Krogdahl A. 2009. The prognostic significance of histological features in oral squamous cell carcinoma. J Oral Pathol Med. 38(8):657-662.

Liebig C, Ayala G, Wilks JA, Berger DH, Albo D. 2009. Perineural invasion in cancer: a review of the literature. Cancer. 115(15):3379-3391

Lowe JS, Anderson PG. 2014. Stevens \& Lowe's human histology. 4th ed. Maryland Heights (MO): Mosby.

Marchesi F, Piemonti L, Mantovani A, Allavena P. 2010. Molecular mechanisms of perineural invasion, a forgotten pathway of dissemination and metastasis. Cytokine Growth Factor Rev. 21(1):77-82.

Maruya SI, Myers JN, Weber RS, Rosenthal DI, Lotan R, El-Naggar AK. 2005. ICAM-5 (telencephalin) gene expression in head and neck squamous carcinoma tumorigenesis and perineural invasion! Oral Oncol. 41(6):580-588.

Miller ME, Palla B, Chen Q, Elashoff DA, Abemayor E, St John MA, Lai CK. 2012. A novel classification system for perineural invasion in noncutaneous head and neck squamous cell carcinoma: histologic subcategories and patient outcomes. Am J Otolaryngol. 33(2):212-215.

Nair S, Singh B, Pawar PV, Datta S, Nair D, Kane S, Chaturvedi P. 2016. Squamous cell carcinoma of tongue and buccal mucosa: clinico-pathologically different entities. Eur Arch Otorhinolaryngol. 273(11):3921-3928.

Panizza BJ. 2016. An overview of head and neck malignancy with perineural spread. J Neurol Surg B Skull Base. 77(2):81-85.
Rahima B, Shingaki S, Nagata M, Saito C. 2004. Prognostic significance of perineural invasion in oral and oropharyngeal carcinoma. Oral Surg Oral Med Oral Pathol Oral Radiol Endod. 97(4):423-431.

Rodolico V, Barresi E, Di Lorenzo R, Leonardi V, Napoli P, Rappa F, Di Bernardo C. 2004. Lymph node metastasis in lower lip squamous cell carcinoma in relation to tumour size, histologic variables and p27Kip1 protein expression. Oral Oncol. 40(1):92-98.

Ross GL, Soutar DS, MacDonald DG, Shoaib T, Camilleri IG, Robertson AG. 2004. Improved staging of cervical metastases in clinically node-negative patients with head and neck squamous cell carcinoma. Ann Surg Oncol. 11(2):213-218.

Sappayatosok K, Phattarataratip E. 2015. Overexpression of claudin-1 is associated with advanced clinical stage and invasive pathologic characteristics of oral squamous cell carcinoma. Head Neck Pathol. 9(2):173-180.

Scanlon CS, Banerjee R, Inglehart RC, Liu M, Russo N, Hariharan A, van Tubergen EA, Corson SL, Asangani IA, Mistretta CM, et al. 2015. Galanin modulates the neural niche to favour perineural invasion in head and neck cancer. Nat Commun. 6:6885.

Shen WR, Wang YP, Chang JY, Yu SY, Chen HM, Chiang CP. 2014. Perineural invasion and expression of nerve growth factor can predict the progression and prognosis of oral tongue squamous cell carcinoma. J Oral Pathol Med. 43(4):258-264.

Sparano A, Weinstein G, Chalian A, Yodul M, Weber R. 2004. Multivariate predictors of occult neck metastasis in early oral tongue cancer. Otolaryngol Head Neck Surg. 131(4):472-476.

Tai SK, Li WY, Chu PY, Chang SY, Tsai TL, Wang YF, Huang JL. 2012. Risks and clinical implications of perineural invasion in T1-2 oral tongue squamous cell carcinoma. Head Neck. 34(7):994-1001.

Tai SK, Li WY, Yang MH, Chang SY, Chu PY, Tsai TL, Wang YF, Chang PM. 2012. Treatment for T1-2 oral squamous cell carcinoma with or without perineural invasion: neck dissection and postoperative adjuvant therapy. Ann Surg Oncol. 19(6):1995-2002.

Tai SK, Li WY, Yang MH, Chu PY, Wang YF. 2013. Perineural invasion in $\mathrm{T} 1$ oral squamous cell carcinoma indicates the need for aggressive elective neck dissection. Am J Surg Pathol. 37(8):1164-1172.

Tang D, Zhang J, Yuan Z, Gao J, Wang S, Ye N, Li P, Gao S, Miao Y, Wang $\mathrm{D}$, et al. 2014. Pancreatic satellite cells derived galectin-1 increase the progression and less survival of pancreatic ductal adenocarcinoma. PLoS One. 9(3): 90476

Tarsitano A, Asioli S, Morandi L, Monti V, Righi A, Morselli Labate AM, Nardi E, Foschini MP, Marchetti C. 2016. Laminin-5 and insulin-like growth factor-II mRNA binding protein-3 (IMP3) expression in preoperative biopsy specimens from oral cancer patients: their role in neural spread risk and survival stratification. J Craniomaxillofac Surg. 44(12):1896-1902.

Tarsitano A, Tardio ML, Marchetti C. 2015. Impact of perineural invasion as independent prognostic factor for local and regional failure in oral squamous cell carcinoma. Oral Surg Oral Med Oral Pathol Oral Radiol. 119(2):221-228.

Yu EH, Lui MT, Tu HF, Wu CH, Lo WL, Yang CC, Chang KW, Kao SY. 2014. Oral carcinoma with perineural invasion has higher nerve growth factor expression and worse prognosis. Oral Dis. 20(3):268-274. 